\title{
An Instinct to Play: An Evolutionary Approach to Pretend Play
}

\author{
Marianna Papadopoulou \\ University of Greenich, United Kingdom
}

\begin{abstract}
This paper employs an ecological framework in order to capture the complex, dynamic, interactive and self-organising nature of children's engagement with their world. Drawing on the principles of ecology it examines parallels between the properties of systems found in nature and children's cognitive and adaptive processes. Similar to ecological systems, children's engagement with the world involves constant and mutually influential interactions between the individual and his/her environment. This interconnectedness and inseparability with the world, termed being-in-the world, enables the exchange of information between the person and the world and thus allows the individual to organise his/her own information structure. Children's being-in-the-world finds its expression in role play. This is the field of mimesis, where children engage in creative appropriation of their real worlds. The play worlds that children create whilst in role play may therefore fulfil self organisational, evolutionary purposes.
\end{abstract}

\section{Introduction}

The thesis proposed in this paper is that the complexity of human existence and, in our case, of young children's processes, can be paralleled with that found in nature. The organisms found in nature (both human and non human) may share certain ecological characteristics that enable them to survive, adapt to their environment, but also to evolve. These are historicity, variability, complexity and changing conditions [1].

Historicity refers to the importance of past events and interactions for the present state and future possibilities. Indeed, the functioning of all organisms, in our case young children's experiences and engagement with their worlds, is based on a temporal horizon; present experiences, emotions, behaviours, interactions, motives, anticipations, and so on, are influenced by past events and experiences, which, in the form of memories (some better realised than others) are always present in thought and action. Similarly, the future possibilities are influenced by the past and present.

An organism's functioning may vary greatly depending on the spatial context. Variability may be caused by a multitude of factors which may often introduce great and unexpected changes to the system under study. In the same fashion, children's engagements with and experiences of their world may vary greatly depending on the individuals involved, the types of interaction, the circumstances, the setting and its demands, or else the context and its conditions.

One of the main, constituting characteristics of systems is the highly complex interactions that are constantly at play [1]. Organisms cannot be seen as autonomous, independent and self sufficient entities. Rather, they are part of webs of interrelationships with other organisms and with their environment. Children's processes and development cannot be seen as taking place in a vacuum. Rather, they are constantly engaged in dynamic and mutually influential interactions with their world.

Such interactions are far from fixed and stable; the environmental conditions are changeable, depending on a host of factors. The experiencing individuals themselves can also impact upon and change the external conditions. At the same time individuals' responses to environment are constantly evolving alongside the changing conditions of the environment. Current patterns of response have evolved as the result of individuals' past responses to environmental conditions. If past responses have proven to be successful for survival and adaptation in a given context they have been preserved as 'fit for purpose' and have thus become part of the organism's behavioural repertoire. On the contrary, responses that prove not to be successful in meeting the demands of a given spatiotemporal context are eliminated [2].

Therefore the dynamic and complex relationship between the organism (the experiencing child) and the 
world is mutually constituting and influential; the person is shaped by the information received from the world, but also the world is shaped by the individual's action upon it. This interdependence between the person and the world, in the form of mutual exchange of information, can make the organism's survival and evolution possible [3]. Or else, the evolutionary adaptation of organisms is only possible due to their ability to receive information from their external world and, using this information, organise their own structures. This process of self-organisation, linked to structural coupling to the environment, is called autopoiesis [4]. Autopoiesis is the active process of self structuring and structuring what counts as an environment for the organism.

It would thus appear that the basis of all behaviours are biological, according to the evolutionary stance. What makes a particular behaviour occur and be either used in future instances, or conversely become extinct, is the degree to which this has in the past resulted in meeting the demands of a continuously evolving environment. Successful environmental adaptation relies on the ability of the organism to appreciate what the environment 'offers' and use these environmental possibilities appropriately in order to structure itself.

However, it is important to make a distinction here: the environment that humans experience and adapt to may not be the same as the environment of other organisms. The environmental challenges that humans face in modern societies may not necessarily involve searching for food and fighting predators (SuttonSmith, 2001). Rather, humans (children, in our instance) face the challenges of adapting to their complex social worlds and developing culturally appropriate skills that will enable socialisation and evolution.

From the beginning of their lives children experience a complex social environment with its values, demands and morals. They encounter different individuals with several roles and systems of relationships. They experience different social environments with different conditions and demands that require different behaviours and skills. In short, young children are constantly surrounded by highly complex cultural systems to which they try to adapt. It would thus be more accurate to name this process 'cultural' evolution.

However, even adaptation to the cultural world may have a biological basis as it involves facing and overcoming basic, primordial, instinctive fears and concerns. Indeed, it may be part of the human condition to experience existential angst about survival and the fear of danger and death. Perhaps many of our everyday behaviours could be seen as attempts to secure and control circumstances in order to feel 'safe' [5]. Our existential concerns could thus be seen as the motive power that informs everyday behaviours and interactions in our cultural and social environment.

Being aware of the demands of a setting, and able to interact and bond with others; to form social networks of relationships, be part of a social group of (similar) others and develop the skills that are required to meet the demands of different settings may be among the behaviours that serve adaptation purposes. They enable individuals to feel 'in control', familiar with their settings, able to predict and manage environmental demands and therefore safe. In short, the characteristics and demands of the cultural settings that 'modern' individuals face and need to adapt to could be seen, at least to an extent, as originated from primordial, existential, biological and survival drives. This would suggest that biological evolution precedes and influences cultural evolution.

To summarise the argument proposed here, according to the ecological perspective, children's worldly experience is highly complex and depends on multiple, dynamic interactions between different systems/agents in a spatiotemporal context. Children are part of the world and at the same time try to make sense of it. Through everyday engagement they encounter and receive information from their environment and organise this into meaningful structures. Their engagement with the world has selforganising purposes. The information children receive from their environment, through their action and agency upon it, is used to facilitate development of the child's own structures and processes.

To put it differently children's activity and engagement with their world enables them to create their own meaning structures (auto-poiein), to develop understanding and make sense of their worlds and themselves in it. Or, in evolutionary terms, to develop the characteristics and skills needed to adapt to their environmental conditions and demands. Evolution and adaptation (either to the natural or cultural worlds) is driven by the biological, existential and deeply seated survival drive that all living organisms share. This survival drive, which may be the basis of both biological and cultural evolution, will be further explored in the following sections.

The argument presented so far suggests that survival and evolution, or, in our case, meaning making and development, are influenced, to a large extent, from the child's agency and interaction with the environment. Autopoiesis and its self organising properties are only achieved through constant and dynamic interactions between the child and his/her world. Role play is one type of engagement with the world that serves self-organisational purposes, as will be discussed later. But first we need to examine the child's agency in this ecological framework. 


\section{Being-in-the-world}

In order to understand the ways in which children gradually construct an understanding of their world and of themselves in it, we need to examine the ways they engage with their environments. According to the ecological framework adopted here human existence, survival, evolution and development, are only possible because of constant, complex and dynamic interactions with the environment.

In phenomenological writings children's experiences are situated in a world, the lived world of everyday experience [6]. All experiences are seen as emerging from and directed towards that world; they are situated in a spatiotemporal context. All behaviours, interactions, intentions, thought processes; but also emotions, desires and attitudes; involve an engaged mind that reaches out to the world. This engagement with the world also presupposes a physical presence, a body that perceives, feels and in other ways lives the experience. The interconnectedness and inseparability between the person and the world is termed as one's being-in-the-world [7].

In the course of everyday living young children encounter unbounded information about the different settings, conditions, demands and objects that comprise the surroundings. They get to know about the function, utility and role of these through their everyday experience. Through their interaction with the world children constitute meaning [6]. In the same fashion, experience of children's everyday worlds is shared with others' being-in-the-world. Their everyday activity is situated in a social network of others, with their own activities, wishes, behaviours and thought processes. They thus learn to engage their everyday settings with those others. The mode of engaging with the social world is called being-in-the-world-withothers [8].

This worldly engagement that phenomenologists propose seems to share common characteristics with the ecological model proposed earlier: the lived world of everyday experience is highly complex and situated in a spatiotemporal context. Indeed, in the course of everyday living children experience different settings, with variable demands and conditions. Their engagement with their world relies on and is influenced by webs of interrelations between children and their environments. Their lived experiences take place and are influenced by different ecosystems in constant and mutual interaction. The notion of beingin-the-world, thus, involves the totality of life: it incorporates body and mind, the person and the world, thought and emotion in a unified, holistic structure.

\section{Intentionality of being and autopoiesis}

Children's engagement is never passive, accidental or purposeless. Staying away from conceptualizations of children as 'empty vessels', waiting to be filled with information by the external world, the argument proposed here is that children's relationship with their world is purposeful. It is always intentional, though not necessarily conscious or uniform.

All mind's activities have a purpose. Consciousness is always consciousness of something [9] (the terms 'mind' and 'consciousness' are used as synonyms here). This purpose impacts on the ways children (and all of us) reach out and relate to their worlds. To put it differently, children's engagement with their worlds is informed by their intentions, some clearer and more conscious than others.

Merleau Ponty [7] makes a distinction between two types of intentions: the first, intentionality of acts, refers to the intentions that the individual is aware and conscious of. They are clear and aim at the realization of an explicit target (in the form of an intention to achieve an outcome). The second type, however, named intentionality of consciousness, may not be as discernible. This type is pre-reflective, largely unconscious, felt rather than known. It may reflect our primordial predispositions, instincts, desires and fears. It is a pre-reflective, pre-thematic mode of being-in-theworld and being-in-the-world-with-others which informs our specific modes of engaging with the world.

To put it differently, where intentionality of acts informs our specific actions, helps put our volitions into action, and is seen as a way of doing and knowing 'how to do', operative intentionality creates those volitions in the first place. It is determined by who we are and how we feel about the world and about ourselves, in the first place. In this sense operative intentionality refers to our mode of Being [6].

Moving back to young children's ecology of being, intentionality of acts relates to their specific volitions, motives and preferences as these are translated into specific actions with a clear target. Their operative intentionalities are the horizon based on which intentional acts are expressed. Operative intentionalities, in the form of unconscious, intuitive and instinctive urges, could be seen as existential, evolutionary drives.

Following the evolutionary argument, our ways of being and engaging with our world are driven by our survival and evolution instincts. Such primordial drives influence our course of action and modes of interacting with our environment. If our main, existential urge is to adapt to our environment, then our operative intentionality predisposes us towards engaging with the different structures of the world, in order to gain information that we can use to organise our structures (to 
make them adaptable and resilient to environmental challenges).

In these terms, children's operative intentionality may drive them towards engaging with their world in certain ways, in order to collect information that they can use in the process of autopoiesis [4]. Engaging with the world enables children to experience its different structures, make sense of the order of things in their world, the function of objects, the role and purpose of different individuals, or ways of relating to others. Such worldly experiences can help children assign meaning to the structures of their world, but also to themselves. They help children develop understandings, skills and competence, and thus develop the structures they need to successfully adapt to their ecological environments (both biological and cultural).

In this sense, everyday experiences of their world can be seen as serving self-organisational purposes. Young children's role play is one such type of worldly engagement that can have an evolutionary function. Orchestrated and directed by the players themselves, this type of play may be particularly useful for self organizational and evolutionary purposes. This will be examined next.

\section{Being-in-the world at role play}

\subsection{The mimetic character of role play}

Play is seen as one of the most significant and distinctive features of childhood. It is something that all children have in common; the type of activity that all children are predisposed to engage with, irrespective of time and setting.

Socio-dramatic play has been conceptualised with reference to its defining characteristics: children undertaking make-believe roles, carrying out makebelieve actions, with make-believe objects and requiring interaction [10]. Whilst cooperating, children take on different identities that complement the identities of their co-players and interact with them as if they were imaginary characters in an imaginary world; a pretend world that is, however, reality bound [11].

The transformation of 'real world' objects, actions and characters into the sphere of play worlds and make believe relies upon the players' ability to engage in symbolic thought; among other cognitive processes employed in cooperative, pretend play settings [12].

Whilst in role play children engage in 'mimesis' [13], a term derived from the Greek 'mimeisthai', which can be translated in two ways. In one reading it means to copy, imitate, or to reproduce a direct copy of the original. In another, 'mimesis' also means to imitate, but rather in a transformative manner. This implies an appropriation, or interpretation, of the original which, in its final version, may not bear any similarities to its original copy at all. This, second, meaning of mimesis is employed to describe artistic expression and interpretation, involving critical receptivity to, and transformation of, the object; a moment of discovery, rather than a mere copy of an original form [13].

Children's sociodramatic play can be seen as a mimesis of their real world. Whilst in play they create settings, produce roles, narratives, plots, interactions, which may be inspired by, and performed according to, their understandings of events and models of real life. However, this play is not a mere copy of their everyday worlds. Rather, it involves children's interpretation of their worlds, their perceptions and meaning-making of events, situations, roles and interactions. Pretend play presents as a process of discovery, here and now, rather than mere reproduction and rehearsal of adult roles [14].

In role play the real and imaginary worlds are in a dialectical relationship. Using the 'raw' material of real life events, children attempt to reproduce it in order to live it, experience its structure, essence and significance, or else, to intend towards it in different ways. It is this dialectical relationship between the two worlds, the real and the imaginary, that makes role play the field for self-organisation and autopoiesis.

\subsection{The play instinct}

The benefits of role play for all areas of development are well documented $[10,11,12,13,14$, $15,16,17]$. The skills that children develop, through pretending, help them gain understandings, knowledge and skills that enable them to deal with environmental challenges. Therefore role playing could be seen as serving adaptive and evolutionary purposes.

Groos [18] extended this evolutionary argument claiming that children do not just play because they are young; rather, they have such a prolonged period of youth because they must play. In his words, 'youth exists for the sake of play' (p. 75). Young children (and young animals) have an instinct to play and this is related to their evolutionary instinct. Play enables them to act upon their environment and develop the skills they need for survival, reproduction and evolution when they reach maturity. The skills that humans need to achieve survival and environmental adaptation are much more complicated than those needed for other animals and this may explain why human youth is so prolonged.

Among other types of play, role play, in particular, appears to be a cultural universal among human children [19], even though its structure and complexity can vary in different settings. All children seem to engage in some form of pretence play, the complexity of which follows a developmental pattern, and this may be evidence of its evolutionary benefits. 
According to Groos [18] in order to pretend players need to understand the mental states of others. This, in turn, requires self awareness and self objectification, or else, the ability to see oneself through the eyes of others. Being able to see multiple perspectives and understand others' thoughts and motives had selective advantages in hominid evolution and therefore such skills are still seen as significant cognitive advantages that assist environmental adaptation [15].

Play experiences, in our case sociodramatic play, could be viewed as children's mode of engaging with their world. Play settings, with their specific conditions, demands, use of objects and presence of others, constitute the field where children encounter limitless information and where their beings-in-theworld assign meaning through their play activity. Participants engage with their play worlds in a purposeful manner, seemingly having a clear volition to play and interact in certain ways. Play worlds offer settings where experiences are lived, where players can act, interact, manipulate objects, where the mind's activity is situated and lives a scenario in an embodied way.

Pretend play could be seen as a highly complex, fully developed, type of play. Whilst in play, children create and recreate meaningful structures. They devise scenarios and assign roles with certain functions, purposes and intentions. These contribute to a meaningful whole, which is the play setting. Thus argued, pretend play is initiated, directed and performed by children themselves so that it illuminates children's modes of perceiving the order of things in their worlds (and their attempts to make sense of their worldly settings) by recreating and reenacting them in different settings.

Following their 'play instinct', the players' operative intentionalities drive them towards constructing scenarios that reflect the complexity they perceive in their ecological environment. Their play narratives enable them to appropriate, examine, rehearse, communicate and thus develop an understanding of the structure of their environmental ecologies. Their play ecologies, inspired by their environmental/cultural ecologies, may facilitate the process of self organization. Pretending to be different characters with specific roles, qualities, purposes and motives, in interaction with other characters enables the players to receive information about the structures of their environment and, through acting, experience it, share it, imagine its impacts and possibilities.

The mythos, or play narrative, gives them the opportunity to experience versions of their worlds that, though creatively appropriated, are still partly parasitic on reality. As such role play is autopoietic; the players organise play ecologies that have a structure, in response to the structure they experience in their 'real' world ecologies. The play ecologies they create can be seen as their attempt to organise their own structures in response to environmental input and information they receive in their everyday lives.

Acting out the chosen scenarios, may assist the autopoietic process [4]. Or else, choosing and acting out certain scenarios, with certain roles in interaction, may be driven by the players' drive to assign meaning to situations (that may have been inspired by situations in real life). Acting out certain roles may help players experience and familiarise themselves with those roles; allowing them to make sense of them and develop the knowledge and skills required in order to face such situations in real life in the future. At the same time, role play can give children the tool to express their deeply seated, existential and primordial fears and concerns, in an attempt to manage, control and perhaps resolve them. Some of these concerns may be developmentally specific. In other words, the ways children experience and relate to their environments could depend on their self perceived (lack of) abilities and power to deal with environmental challenges at a particular point in their development. This function of role play will be examined next.

\subsection{Play and development}

The complexity of the play ecologies that children construct varies depending on their developmental stage. Development here is understood as a process through which the individual gradually develops the skills and competences that will make him/her successful in adapting to the structures of the ecological environment.

As children develop their relationship their environment changes [2]. Their emerging skills allow them to explore, experiment with, act upon and make sense of their environmental ecology in progressively more complex and effective ways. In evolutionary terms, the ways in which children of different ages relate to their environment is based on the skills they have at that particular point in their lives to meet environmental challenges. Their response to potential environmental threats depends on the degree of vulnerability they perceive themselves as having in dealing with these.

Some of the most important ecological challenges, such as safety, foraging and feeding and finding a shelter [2] may be experienced by humans and animals at all stages of development, but be expressed in different, age related and skill dependent behaviours: maintaining safety for an immobile infant may be expressed through fear of strangers and associated protests when the carer is out of sight. For a young child who can walk and roam about, danger may take the form of fear of getting lost. 
Role play can thus give children the opportunity to express and attempt to control and manage such existential concerns. Acting out the roles of superheroes, parents, or any other powerful agents may give the players a sense of power and ability to deal with dangers and threats. Such pretence scenarios can help soothe their fears and self perceived powerlessness experienced in real life.

As a mode of being-in-the-world, the play world is very different from children's everyday worlds, where their lives are controlled and, to a large extent, decided by others. In pretend play children have the freedom to invent their own scenario and the power to make decisions regarding the roles they perform, the events that unfold and the circumstances they act out. In phenomenological terms, the play world offers the setting where children's beings-in-the-world can intend towards their play world in ways they can control and manipulate.

As such, the play worlds, invented, negotiated and performed by the players themselves may be reflective of their implicit, primordial and unconscious intentionalities. The scenarios they devise, the roles they invent and the types of activity and interaction these roles engage in may reflect the players' unrealised and unconscious drives to experience the given scenarios, live them, feel them, engage with them, in order to make sense of them and even control them. These operative intentionalities are fulfilled through the specific, intentionalities of acts - the play behaviours.

Play behaviours, in turn, may reflect the players' present existential concerns based on their stage of development. Their operative intentionalities inform them about the aspects of their environment that are potentially dangerous, or friendly, manageable, or out of reach, understandable or unknown and puzzling, interesting or irrelevant, always in relation to their self perceived current abilities and skills. Their play themes may therefore reflect their attempt to familiarise with and develop the capacities required to deal with certain challenges of their environmental/cultural ecologies.

\section{Conclusion}

The significance and benefits of role play for language, cognitive and socio-emotional development are well documented. The purpose of this work, however, has been to examine the evolutionary purposes that role play may serve. Drawing parallels with ecological systems found in nature, the thesis presented here is that children's experiences of and engagement with their worlds should be seen in an ecosystem of dynamic and constant interactions between the children and their worlds. Such interactions are situated in a spatiotemporal context and are characterised by children's agency and active engagement with their worlds.

The children's being-in the world is intentional, with some intentions being clearer and easier to recognise than others. The less recognizable, primordial and unconscious operative intentionalities may otherwise be seen as the evolutionary instincts that drive children towards acquiring skills and knowledge that helps them adapt to their environment. The process of development can otherwise be seen as the process of gradually acquiring knowledge, competences and experiences that will enable the person, or organism, to adapt to and meet the challenges of its environment.

At the same time, role play narratives, devised and orchestrated by the players themselves, can be seen as the children's attempt to come to terms with and control their deeply seated, unconscious and existential fears.

Under the evolutionary light, children's engagement with their worlds serves survival and adaptation purposes. Their everyday experiences of their worlds, and their role play experiences in particular, enable them to experience their play worlds, which are creatively adapted from their everyday, real worlds. Acting out different scenarios, inspired from the raw material of real life, enables the children to gain experiences that would otherwise be impossible to attain. In this manner, role play gives them information about the structure of their world and enables them to develop their own structures in response to their play experiences. This process of autopoiesis (making oneself) can thus be seen as the development of skills that are crucial for adaptation and thus evolution.

\section{References}

[1] Reiners, W. A. and Lockwood, J. A. (2010) Philosophical Foundations for the Practices of Ecology, Cambridge University Press, Cambridge.

[2] Heerwagen, J. H. and Orians, G. H. (2002) 'The Ecological World of Children', in P. H. Kahn and S. R. Kellert (Eds) Children and Nature: Psychological, Sociocultural and Evolutionary Investigations, MA: MIT Press, Cambridge.

[3] Smith, J. and Jenks, C. (2006) Qualitative Complexity, Routledge, London and New York.

[4] Maturana, U. and Varela, F. (1980) Autopoiesis and Cognition, D. Reidel, Dordrecht.

[5] Sutton-Smith, B. (2001) The Ambiguity of Play, Harvard University Press, London. 
[6] Papadopoulou, M. and Birch, R. (2008) 'Being-in-the world: the event of learning', Educational Philosophy and Theory, 41(3), pp. 270-86.

[7]Merleau Ponty, M. (1962) Phenomenology of Perception, Routledge and Kegan Paul, London.

[8] Heidegger, M. (1935) Existence and Being, Cambridge University Press, Cambridge.

[9] Kockelmans, J. (ed.) (1967) Phenomenology. The Philosophy of Edmund Husserl and its Interpretation, Doubleday \& Company Inc, New York.

[10] Smilansky, S. (1990) 'Sociodramatic Play: its Relevance to Behaviour and Achievement in School', in S. Smilansky \& E. Klugman (eds) Children's Play and Learning: Perspectives and Policy Implications, Teachers College Press, New York.

[11] Smilansky, S., and Shefatya, L. (1990) Facilitating Play: A Medium for Promoting Cognitive, Socio-Emotional and Academic Development in Young Children, Silver Springs, MD: Psychosocial and Educational Publications, USA.

[12] Bergen, D. (2002) 'The Role of Pretend Play in Children's Cognitive Development', Early Childhood Research and Practice, 4(1).

[13] Guss, F. (2005) 'Reconceptualising Play: aesthetic selfdefinitions', Contemporary Issues in Early Childhood, 6(3), pp. 233-43.

[14] Thyssen, S. (2003) 'Child Culture, Play and Child Development', Early Child Development and Care, 173(6), pp. 589-612.

[15] Piaget, J. (1962) Play, Dreams and Imitation in Childhood, W. W. Norton and Company Inc., New York.

[16] Freud, S. (1920) 'Beyond the Pleasure Principle', in Strachey, J. (ed) The Standard Edition of the Complete Psychological Works of Sigmund Freud, Vol. XVII, The Hogarth Press, London.

[17] Ashiabi, G. (2007) 'Play in the Preschool Classroom: its socioemotional significance and the teacher's role in play', Early Childhood Education Journal, 35(2), pp. 199-207.

[18] Groos, K. (1898) The Play of Animals, Appleton, New York.

[19] Pelegrini, A. D. and Smith, P. K (Eds) (2005) The Nature of Play. Great Apes and Humans, The Guidlford Press, London. 